\title{
HIGH VISIBILITY REFLECTIVE SIGN SHEETING MATERIALS: FIELD AND COMPUTATIONAL EVALUATIONS OF VISUAL PERFORMANCE
}

\author{
John D. Bullough, Nicholas P. Skinner \\ Lighting Research Center, Rensselaer Polytechnic Institute, United States
}

Submitted 11 December 2015; resubmitted 14 August 2016; accepted 23 August 2016;

published online 20 October 2016

\begin{abstract}
Highway signs provide important information to drivers to assist in navigation, to identify potentially hazardous roadway locations, and to remind drivers of safe operating practices. Ensuring that signs have sufficient visibility to the driving public is a key undertaking by transportation agencies. In order to assist in evaluating and comparing different materials for photometric and visual performance, the present study was undertaken to assess the utility of specifying sign sheeting performance in terms of visual performance. As part of this effort, a practical methodology for conducting field measurements of sign luminance along roadways was developed. In addition to describing the methods for an approach to visual performance based specifications, a spreadsheet tool for calculating minimum sign luminance and visibility from different sign sheeting materials was also developed.
\end{abstract}

Keywords: retroreflective signs; visual performance; sign legibility; sheeting materials.

\section{Introduction}

Highway signs are critical elements of the roadway infrastructure, providing important information to drivers to assist in navigation, to identify potentially hazardous roadway locations, and to remind drivers of safe operating practices. In the US, the Manual on Uniform Traffic Control Devices (MUTCD) requires that guide signs (containing destination and exit information) be either illuminated or retroreflective. In many locations in New York State, overhead guide signs often use both retroreflective materials and external illumination. External sign lighting systems have high installation and operating costs, require difficult maintenance especially in urban locations with high traffic densities, and can contribute to light pollution. Using materials with sufficient retroreflectivity to ensure good nighttime visibility might make sign lighting unnecessary in some situations. However, it is also desirable to ensure that retroreflectivity is not superfluous to visibility in order to prevent excessive costs.

The present paper describes research activities undertaken to assist transportation agencies in evaluating sign material types based on their existing performance specifications. The primary method used to characterize the visibility of signs in this paper is the Relative Visual Performance (RVP) model (Rea, Ouellette 1991).
Specifications for the performance of retroreflective sign materials such as those published by the American Society for Testing and Materials (ASTM D4956-16) are given in terms of photometric performance such as the luminance of the sign material for a given illuminance $\left[\mathrm{cd} / \mathrm{lx} / \mathrm{m}^{2}\right]$ under specific geometric conditions. In the laboratory and in the field, photometric measurements of the luminance of a sign can be made. By themselves, these photometric quantities do not translate directly into meaningful measures of visibility, because visibility depends not only on the luminance but on other factors. The RVP model (Rea, Ouellette 1991) is a calculation model that predicts the speed and accuracy of visual processing for different combinations of several important visual parameters:

- background luminance;

- luminance contrast between target and background;

- target size;

- observer age.

RVP values range from zero at the threshold of object identification, to one under a reference condition corresponding to reading large, high-contrast printed text on white paper under office light levels (500 lx). RVP values even higher than one are possible with even higher contrast, larger size or higher light levels. RVP

Corresponding author: John D. Bullough

E-mail: bulloj@rpi.edu 
is proportional to the speed of visual processing. RVP quantities tend to exhibit a plateau and escarpment quality whereby once light level, contrast and size provide a high level of visual performance, further increases in any of these factors will not substantially improve visual performance (it is said to be on the plateau). However, if light level, contrast or size were to decrease enough to place visual performance on the edge of the plateau, even small reductions in any of these factors could result in large decrements in visibility.

Quantities derived from the RVP model were highly correlated with visual acquisition times for simulated overhead guide signs varying in luminance and contrast, measured by Schnell et al. (2009). RVP quantities were also highly correlated with symbol orientation identification times in a separate laboratory study of highway sign visibility (Goodspeed, Rea 1999). The RVP model is used in this study as a way to describe the visibility of sign symbols and characters based on their luminance, contrast, and size characteristics, for different geometric conditions and by drivers varying in age. First, however, it was necessary to conduct field measurements to identify the range of luminances of guide signs in an existing real-world sign installation.

\section{Sign Luminance Field Measurements}

\subsection{Method}

Several guide signs (white characters on a green background) along the Bruckner and Cross-Bronx Expressways in New York City were installed using two different high visibility reflective sign sheeting materials. Specifically, Type IX and Type XI sheeting meeting the ASTM D4956-16 specifications for retroreflective sign sheeting materials were installed. In general, these specifications require higher levels of retroreflectivity in $\left[\mathrm{cd} / \mathrm{lx} / \mathrm{m}^{2}\right]$ than sheeting materials meeting Type III designations. Which sign panels used which materials were unknown to the project team until after all field measurements were made.

The overhead guide signs that were selected for field measurement, and the relevant viewing distances, selected in cooperation with the New York State Department of Transportation (NYSDOT), are shown in Fig. 1. Most of the viewing distances for the selected signs were between 430 and $660 \mathrm{ft}$ (130 and $200 \mathrm{~m}$ ) from the signs. Since both the background and sign characters used the same sheeting types, and since previous measurements (Bullough et al. 2010) showed that the relative luminance contrast between the green background and the white characters was constant when they used the same material types, only the green backgrounds were measured. This permitted measurements to be made without complex optical accessories in place that would be required to measure the luminance of individual characters, which would increase the scatter within the photometric instrumentation and reduce measurement precision.

Photometric measurements were made using a narrow-angle luminance meter (Minolta LS-110) with a $0.33^{\circ}$ aperture. The procedure developed in conjunction with NYSDOT was to measure the signs along the northbound direction of the expressway containing the signs to be measured, and then to turn around and measure the signs in sequence along the southbound direction. Two nighttime sets of measurements were made, one in the fall of 2013 (session 1) and one in the fall of 2014 (session 2). The measurements occurred during
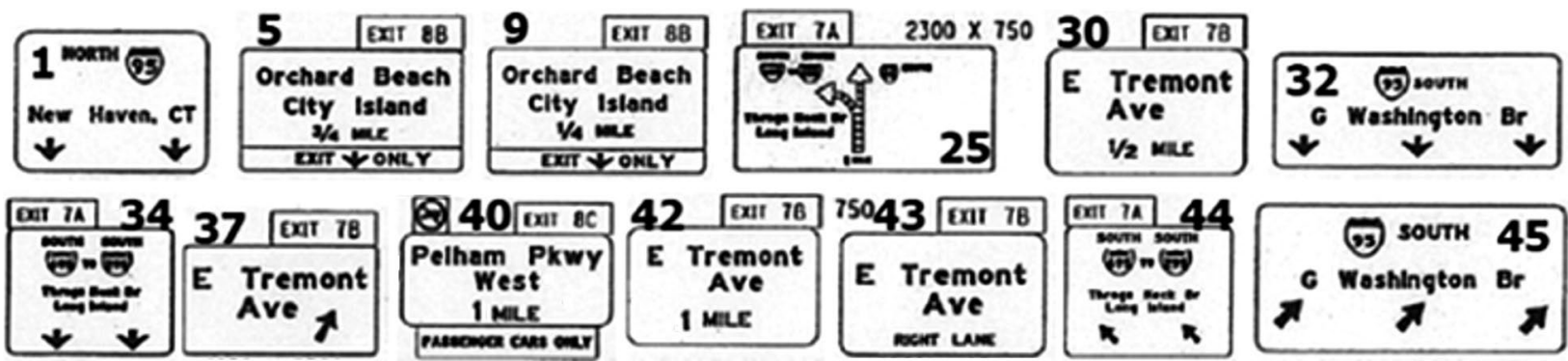

\begin{tabular}{|c|c|c|c|c|c|c|}
\hline Location number & Sign number(s) & Direction & Mounting & Distance & Viewing station & Comments \\
\hline 8 & 9 & NB & Arm & 150 & $8+840$ & \\
\hline 4 & 40,5 & NB & OH Structure & 150 & $8+140$ & \\
\hline 1 & 1,1 & NB & OH Structure & 200 & $7+695$ & \\
\hline 24 & 25,42 & SB & Bridge & 130 & $9+280$ & \\
\hline 30 & $34,32,30$ & SB & OH Structure & 200 & $8+490$ & Best view from LEFT Lane \\
\hline 33 & $34,32,43$ & SB & OH Structure & 200 & $8+095$ & \\
\hline 36 & $34,32,37$ & SB & OH Structure & $200^{\star}$ & $7+850$ & ${ }^{\star}$ View at $150 \mathrm{~m}$ also, $7+800$ \\
\hline $38 \mathrm{~A}$ & 44,45 & SB & OH Structure & 135 & $7+650$ & \\
\hline
\end{tabular}

Distances in meters

Fig. 1. Guide signs and locations selected for the initial field measurement sample. Also shown are the viewing distance(s) and mounting type for each sign. Multiple sign numbers appear at different locations when duplicate sign panels appeared before a highway exit 
dry, clear weather with no condensation present on the sign panels.

During both sessions, researchers rode in a passenger vehicle operated by a NYSDOT engineer. One researcher used a LIDAR range finder (Bushnell) to measure the distance to the signs from the front passenger side seat, and another sat in the seat behind the driver and measured luminances over the shoulder of the driver to simulate the driver's line of sight. All measurements were made through the front windshield. As close as practical to the designated measurement distance, a luminance measurement was made for each sign panel at that location with the passenger vehicle's low beam headlamps switched on. Then, a second luminance measurement was made for each sign panel with the low-beam headlamps of the passenger vehicle switched off. The measurements at each location typically took between 1 and 2 minutes. All measurements were made from the rightmost traffic lane.

\subsection{Session 1 Measurements}

Table 1 lists the ASTM types and measured luminance values of each of the signs measured during session 1 , as well as the differences between each pair of values with headlamps switched on and off. This difference provides an estimate of the retroreflective luminance of the signs while disregarding luminance from ambient light along the highway from other sources of light. The maximum retroreflective luminance was $17.9 \mathrm{~cd} / \mathrm{m}^{2}$ and the lowest retroreflective luminance was $0.8 \mathrm{~cd} / \mathrm{m}^{2}$.

Table 1. Summary of photometric measurements and retroreflective luminances for each of the measured signs in session 1

\begin{tabular}{|c|c|c|c|c|}
\hline \multirow[b]{2}{*}{ Location } & \multirow{2}{*}{$\begin{array}{c}\text { ASTM } \\
\text { type }\end{array}$} & \multicolumn{2}{|c|}{ Luminance $\left[\mathrm{cd} / \mathrm{m}^{2}\right]$} & \multirow{2}{*}{$\begin{array}{c}\text { Difference } \\
{\left[\mathrm{cd} / \mathrm{m}^{2}\right]}\end{array}$} \\
\hline & & $\begin{array}{c}\text { headlights } \\
\text { on }\end{array}$ & $\begin{array}{c}\text { headlights } \\
\text { off }\end{array}$ & \\
\hline \multicolumn{5}{|c|}{ Northbound } \\
\hline 1 & XI & 6.0 & 4.0 & 2.0 \\
\hline 1 & XI & 7.3 & 4.4 & 2.9 \\
\hline $4 \& 30$ & IX & 2.8 & 1.8 & 1.0 \\
\hline $4 \& 30$ & XI & 6.3 & 2.4 & 3.9 \\
\hline 8 & IX & 3.2 & 1.8 & 1.4 \\
\hline \multicolumn{5}{|c|}{ Southbound } \\
\hline 24 & IX & 2.2 & 0.9 & 1.3 \\
\hline 24 & $\mathrm{XI}$ & 3.5 & 1.5 & 2.0 \\
\hline $4 \& 30$ & IX & 2.5 & 1.1 & 1.4 \\
\hline $4 \& 30$ & XI & 2.1 & 1.1 & 1.0 \\
\hline 33 & IX & 4.1 & 1.1 & 3.0 \\
\hline 33 & XI & 2.7 & 1.5 & 1.2 \\
\hline 33 & XI & 4.1 & 2.2 & 1.9 \\
\hline $36(199 \mathrm{~m})$ & $\mathrm{XI}$ & 6.4 & 3.5 & 2.9 \\
\hline $36(199 \mathrm{~m})$ & XI & 22.3 & 4.4 & 17.9 \\
\hline $36(160 \mathrm{~m})$ & XI & 3.9 & 1.7 & 2.2 \\
\hline $36(160 \mathrm{~m})$ & XI & 5.9 & 3.8 & 2.1 \\
\hline $38 \mathrm{~A}$ & IX & 1.7 & 0.9 & 0.8 \\
\hline $38 \mathrm{~A}$ & $\mathrm{XI}$ & 3.9 & 1.1 & 2.8 \\
\hline
\end{tabular}

\subsection{Session 2 Measurements}

Table 2 lists the ASTM types and measured luminance values for session 2, as well as the differences between each pair of values with headlamps switched on and off. This difference provides as estimate of the retroreflective luminance of the signs while disregarding luminance from ambient light along the highway from other sources of light. The maximum retroreflective luminance was $4 \mathrm{~cd} / \mathrm{m}^{2}$ and the lowest retroreflective luminance was $0.1 \mathrm{~cd} / \mathrm{m}^{2}$.

Table 2. Summary of photometric measurements and retroreflective luminances for each of the measured signs in session 2

\begin{tabular}{|c|c|c|c|c|}
\hline \multirow[b]{2}{*}{ Location } & \multirow{2}{*}{$\begin{array}{l}\text { ASTM } \\
\text { type }\end{array}$} & \multicolumn{2}{|c|}{ Luminance $\left[\mathrm{cd} / \mathrm{m}^{2}\right]$} & \multirow{2}{*}{$\begin{array}{c}\text { Difference } \\
{\left[\mathrm{cd} / \mathrm{m}^{2}\right]}\end{array}$} \\
\hline & & $\begin{array}{c}\text { headlights } \\
\text { on }\end{array}$ & $\begin{array}{l}\text { headlights } \\
\text { off }\end{array}$ & \\
\hline \multicolumn{5}{|c|}{ Northbound } \\
\hline 1 & $\mathrm{XI}$ & 5.6 & 2.1 & 3.5 \\
\hline 1 & $\mathrm{XI}$ & 5.9 & 4.5 & 1.4 \\
\hline $4 \& 30$ & IX & 2.2 & 1.6 & 0.6 \\
\hline $4 \& 30$ & XI & 3.6 & 2.7 & 0.9 \\
\hline 8 & IX & 1.8 & 0.7 & 1.1 \\
\hline \multicolumn{5}{|c|}{ Southbound } \\
\hline 24 & IX & 3.6 & 2.1 & 1.5 \\
\hline 24 & XI & 5.0 & 3.7 & 1.3 \\
\hline $4 \& 30$ & IX & 2.7 & 1.5 & 1.2 \\
\hline $4 \& 30$ & XI & 3.3 & 1.5 & 1.8 \\
\hline 33 & IX & 1.6 & 0.8 & 0.8 \\
\hline 33 & XI & 2.6 & 0.8 & 1.8 \\
\hline 33 & $\mathrm{XI}$ & 3.6 & 1.1 & 2.5 \\
\hline $36(210 \mathrm{~m})$ & $\mathrm{XI}$ & 3.6 & 3.2 & 0.4 \\
\hline $36(210 \mathrm{~m})$ & $\mathrm{XI}$ & 8.6 & 4.6 & 4.0 \\
\hline $36(150 \mathrm{~m})$ & $\mathrm{XI}$ & 2.2 & 1.1 & 1.1 \\
\hline $36(150 \mathrm{~m})$ & $\mathrm{XI}$ & 3.9 & 2.7 & 1.2 \\
\hline $38 \mathrm{~A}$ & IX & 0.8 & 0.7 & 0.1 \\
\hline $38 \mathrm{~A}$ & XI & 2.0 & 1.5 & 0.5 \\
\hline
\end{tabular}

\subsection{Comparison Between Sessions 1 and 2}

Although the measured values in session 2 were generally lower than they were for session 1 (about 40-50\% lower, on average), a paired, two-tailed Student's $t$-test revealed that the difference between the sets of measurements was not statistically significant $(p>0.05)$, an unsurprising finding given the limited sample size. There was, however, a modest but statistically significant correlation between the corresponding sets of measurement values $(r=+0.59, p<0.01)$, indicating that the brightest signs in session 1 tended to be brightest in session 2 , and the dimmest in session 1 tended to be dim in session 2 . In fact, the brightest sign in each measurement set, as well as the dimmest, were the same. The correlation between the sessions suggests a degree of consistency between the measurements. However, since the sign with the highest luminance in each session was so 
much brighter than the others, the statistical strength of the correlation depends in large part on this pair of measurement values, and the correlation, while promising, should be interpreted cautiously.

The lower luminances for the second set relative to the first is probably not related to the fact that the second session occurred a year after the first. This is because sign retroreflectivity degradation studies have typically found annual retroreflectivity degradation rates of about $2 \%$ per year - summarized by Ré et al. (2011), not $40-50 \%$ as would be suggested by the luminance measurements in sessions 1 and 2. During the second session, experimenters observed that the vertical aim cutoff of the headlamps used in the measurement vehicle was substantially lower during the second set of measurements than it was during the initial set. Vertical downward aim of automotive headlights is not uncommon on vehicles in the US (Skinner et al. 2010). It seems likely, given this observation, that the differences in measured luminances were largely caused by the difference in headlamp aim between sessions. Bullough et al. (2010) similarly found systematic differences in sign luminance were caused by differences in headlamp conditions between measurement sessions.

There was a statistically significant difference (Mann-Whitney test, $p<0.05$ ) between the luminances of the Type IX (session 1: $1.6 \mathrm{~cd} / \mathrm{m}^{2}$, session $2: 0.9 \mathrm{~cd} / \mathrm{m}^{2}$ ) and Type XI (session 1: $3.1 \mathrm{~cd} / \mathrm{m}^{2}$, session $2: 1.7 \mathrm{~cd} / \mathrm{m}^{2}$ ) materials. On average, the luminances of the Type IX materials were $54 \%$ of the luminances of the Type XI materials. This corresponds well with the specified minimum differences between these two ASTM D4956-16 types for the geometric conditions associated with the measurements, where the specified minimum retroreflectivity for Type IX materials is $57 \%$ of the specified minimum for Type XI materials.

\subsection{Summary of Field Measurements}

The previous results indicate that field luminance measurements have some value for assessing the visibility characteristics of highway signs, but that there are also important caveats. The primary caveat is that the absolute value of the luminances depends very strongly on the type and conditions of the headlamps used when making the measurements. Nominally, identical measurements were made in each session, but observed differences in headlamp vertical aim resulted in large (40$50 \%)$ differences in the measured luminances.

Nonetheless, the technique of subtracting the influence of ambient light appears to be a practical way to evaluate the influence of vehicle headlamps alone on retroreflective sign luminance. In addition, the correlation between the measured values in each session, as well as the differences between sign material types that were consistent with the ASTM D4956-16 type specifications, suggests that it is possible to differentiate among different sign sheeting material types based on field luminance measurements.

\section{Visual Performance Analyses}

Since the measured signs were all guide signs using green backgrounds with white letters, the analysis of retroreflective luminances presented in this session is based on overhead sign geometry using green as the color of the background sign sheeting. A sign height of $21.5 \mathrm{ft}$ $(6.6 \mathrm{~m})$ was assumed as well as a headlamp height of $2.79 \mathrm{ft}(0.85 \mathrm{~m})$ and a driver eye height of $4.83 \mathrm{ft}(1.5 \mathrm{~m})$, based on normative data published by Carlson et al. (2010). A forward tilt of $3^{\circ}$ was also assumed. For the headlamps, data representing a 2004 US-market-weighted low beam pattern (Schoettle et al. 2004) were used to estimate the luminous intensity from the headlamps in the direction of the signs. While other headlamp intensity distribution data could be used, a primary purpose of the visual performance analyses was to characterize differences between different sheeting material types, and different assumed headlamp patterns would still result in the same illuminance being produced on a sign for any given geometry. Every $100 \mathrm{ft}(30.5 \mathrm{~m})$ between $200 \mathrm{ft}(61 \mathrm{~m})$ and $1000 \mathrm{ft}(305 \mathrm{~m})$ from the sign, the entrance and observation angles were calculated for the light source/driver/sign geometry, and the luminous intensity from two headlamps in the direction of the sign was calculated. As an approximation, both headlamps were assumed to be directly in the center of the vehicle behind the sign; this resulted in a maximum horizontal angle error of $0.5^{\circ}$. Using the inverse-square law, it was possible to estimate the illuminance on the sign according to the relationship:

$$
E=\frac{I}{d^{2}},
$$

where: $E$ is the illuminance on the sign $[\mathrm{lx}] ; I$ is the sum of the luminous intensities from the pair of headlamps [cd]; $d$ is the distance to the sign [m], converted from $\mathrm{ft}$ to ensure proper units of illuminance.

Table 3 shows, for distances from the sign between $200 \mathrm{ft}(61 \mathrm{~m})$ and $1000 \mathrm{ft}(305 \mathrm{~m})$, the resulting entrance and observation angles and the illumination on the sign. The columns in Table 3 corresponding to the entrance and observation angles have color-coded shading based on the typical angles included in the published specifications (ASTM D4956-16). For example, if the observation angle is equal to or less than $0.5^{\circ}$ but greater than $0.2^{\circ}$, the reference observation angle used to estimate the sign luminance is $0.5^{\circ}$. It is assumed that the actual coefficient of retroreflection at angles less than a particular angle will be at least the same value as at the next largest reference angle. Similarly, entrance angles in Table 3 are color coded based on the next largest reference entrance angle (either 4 or $30^{\circ}$ ).

Finally, in order to estimate the luminance as observed by a driver, a windshield transmittance of $80 \%$ is assumed in the present analyses, which is a typical value based on several field measurements conducted by the authors. 
Table 3. Geometric and illumination conditions from low-beam headlamp illumination for overhead guide signs viewed from difference distances

\begin{tabular}{|c|c|c|c|c|}
\hline $\begin{array}{c}\text { Distance } \\
{[\mathrm{ft}]}\end{array}$ & $\begin{array}{c}\text { Average observation angle } \\
{[\mathrm{deg}]}\end{array}$ & $\begin{array}{c}\text { Average entrance angle } \\
{[\mathrm{deg}]}\end{array}$ & $\begin{array}{c}\text { Intensity toward sign } \\
{[\mathrm{cd}]}\end{array}$ & $\begin{array}{c}\text { Illuminance on } \\
\text { sign }[\mathrm{lx}]\end{array}$ \\
\hline 200 & 1.00 & 2.40 & 275 & 0.0740 \\
\hline 300 & 0.65 & 0.70 & 446 & 0.0533 \\
\hline 400 & 0.47 & 0.40 & 552 & 0.0371 \\
\hline 500 & 0.37 & 0.90 & 670 & 0.0288 \\
\hline 600 & 0.31 & 1.20 & 763 & 0.0228 \\
\hline 700 & 0.26 & 1.45 & 877 & 0.0193 \\
\hline 800 & 0.23 & 1.70 & 1008 & 0.0170 \\
\hline 900 & 0.20 & 1.83 & 1167 & 0.0155 \\
\hline 1000 & 0.18 & 1.95 & 1288 & 0.0139 \\
\hline
\end{tabular}

Fig. 2 shows, for each of the ASTM D4956-16 sign material types, the minimum luminances that can be expected from low beam headlamps for the geometric conditions listed in Table 3, plotted as a function of the distance from the sign. Each of the curves in Fig. 2 are composed of different segments; each segment corresponds to a particular range of observation angles (i.e., less than $1^{\circ}$ but greater than $0.5^{\circ}$, less than $0.5^{\circ}$ but greater than $0.2^{\circ}$, and less than $0.2^{\circ}$ ). All of the entrance angles for all viewing distances are less than $4^{\circ}$. Some curves (i.e., for ASTM types I and II) have no values for distances less than $400 \mathrm{ft}(122 \mathrm{~m})$ because the specified definitions of these types do not include observation angles greater than $0.5^{\circ}$, and there is therefore no definition of minimum performance for the materials represented by these curves.

It should also be emphasized that the luminance values in Fig. 2 are minimum values based on the limited angles included in the material type specifications, not luminances likely to be experienced in the field. For a particular sheeting material of any these types, the actual luminance for any particular geometry in the field could be substantially higher than represented by the curves in Fig. 2. With a full set of measurement data corresponding to angles at much smaller intervals than the tabulated retroreflectivity data published by ASTM D4956-16 it would be possible to provide more accurate estimates of the sign luminances for a given geometry, but it is critical to understand that the ASTM D495616 type specifications are limited in the angles at which actual performance is specified. Therefore, the data in Fig. 2 represent a floor, below which the luminances would not be expected to fall, for each material type.

By themselves, the curves in Fig. 2 do not indicate whether the information on a sign with those luminances would be legible. Using the RVP model (Rea, Ouellette 1991), such analyses can be made. It is assumed, based on measurement data from Bullough et al. (2010) for overhead guide signs, that the luminance contrast between the green background and the white letters on the signs is 0.8 , and that the character size of interest is a 16 inch $(40.5 \mathrm{~cm})$ letter height. A driver age of 60 years is assumed, this being at the upper limit of the RVP model, beyond which systematic changes in the visual system begin to break down, and substantial variations among individuals can be found.

For sign characters corresponding to these assumptions, and using the sign luminance values in Figs 2 and 3 shows the resulting RVP values for each of the ASTM D4956-16 sheeting material types.

These curves provide the user with quantitative comparison of the minimum RVP that each material type could provide under a particular geometric and headlighting condition. The usefulness of these curves can be illustrated by comparing the luminance and RVP curves in Figs 2 and 3 with the measured data from the field measurements described previously in this paper. Fig. 4 shows the measured luminances for each measurement session plotted as a function of the distance at which they were measured, alongside the luminance curves for the ASTM D4956-16 types.

Most of the measured luminances in Fig. 4 exceed the minimum values expected of most of the sign material types. One sign in the second measurement session had a relatively low luminance $\left(0.1 \mathrm{~cd} / \mathrm{m}^{2}\right)$. Using the RVP model (Rea, Ouellette 1991), the RVP values corresponding to the visual performance of 16-in. characters on the sign by 60 -year-old drivers at the measured distances were calculated. Fig. 5 shows the measured RVP alongside the ASTM D4956-16 sign material types.

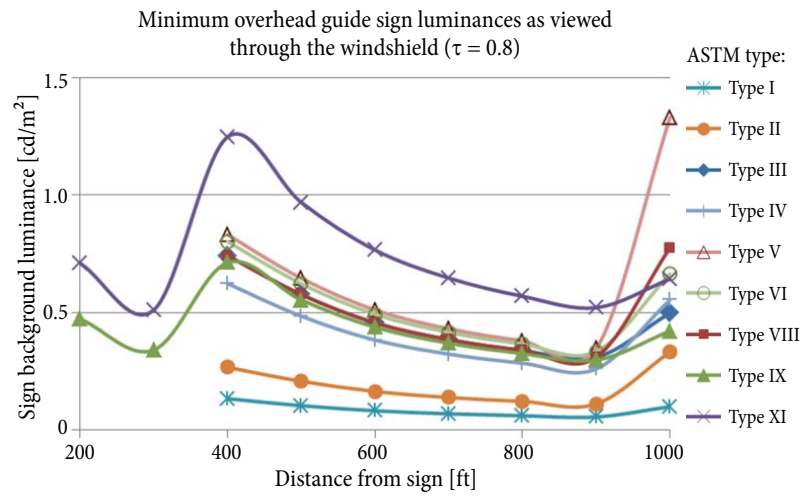

Fig. 2. Minimum overhead sign luminance, as a function of distance from the sign, for each of the ASTM D4956-16 sheeting types 


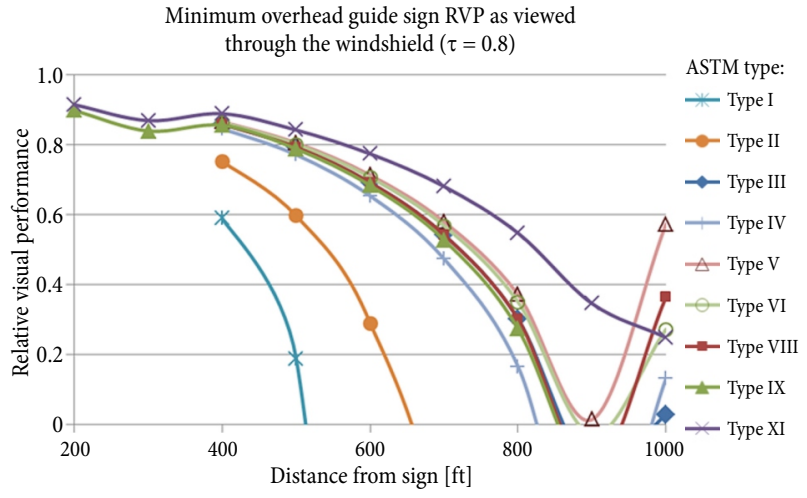

Fig. 3. Minimum RVP values for each ASTM D4956-16 sign material type, as a function of viewing distance, for a 60 -year-old driver

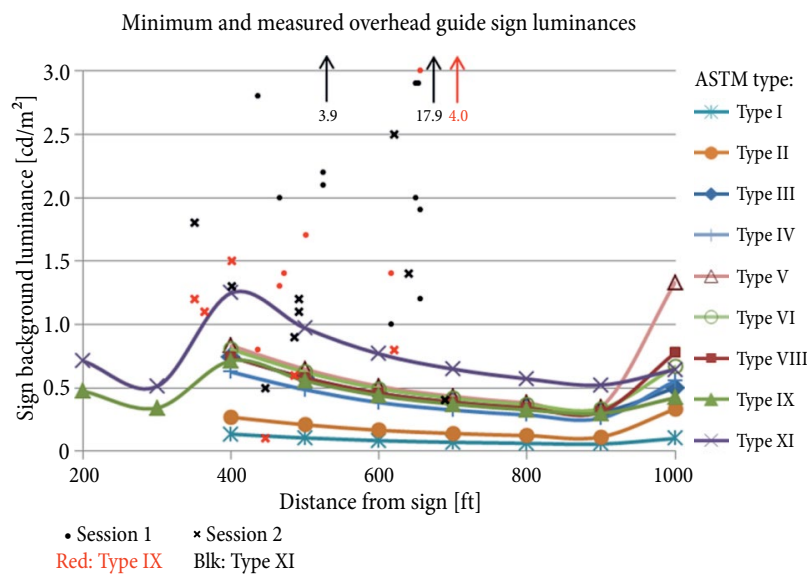

Fig. 4. Measured sign luminances for both measurement sessions, plotted as a function of the measurement distance. Also shown are the minimum luminances expected for each ASTM D4956-16 sign material type; different symbol shapes/ colors represent different sessions and sheeting materials

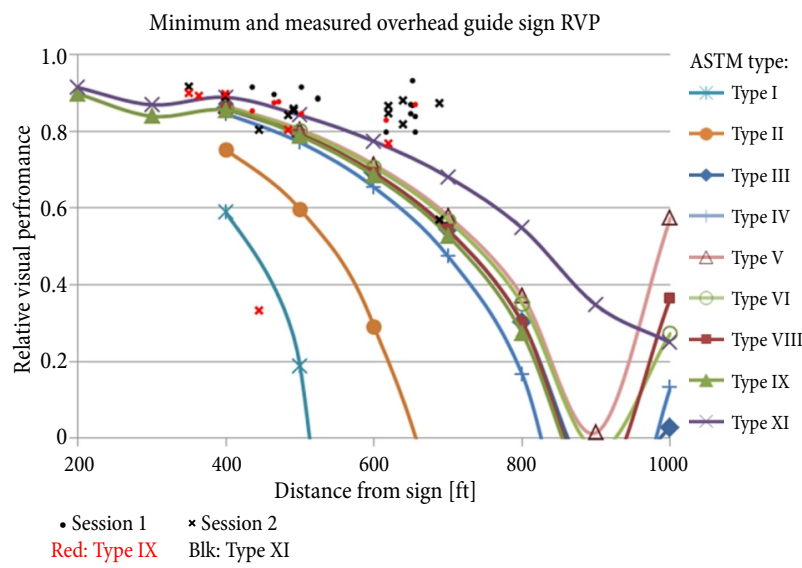

Fig. 5. RVP values corresponding to the measured luminances and distances, compared with the minimum RVP values expected for each ASTM D4956-16 material type (different symbol shapes/colors represent different sessions and sheeting materials)
The data in Figs 4 and 5 clearly illustrate the plateau nature of RVP (Rea, Ouellette 1991). Despite large variations in measured luminance values in Fig. 4 (from 0.1 to $17.9 \mathrm{~cd} / \mathrm{m}^{2}$, a greater than hundredfold range), the RVP values in Fig. 5 exhibit much less variation (from 0.3 to 0.9 , a range of about three to one). Almost all RVP values, with the exception of one sign from session 2 with the lowest $\left(0.1 \mathrm{~cd} / \mathrm{m}^{2}\right)$ measured luminance, are near or above the curves corresponding to ASTM material types IX and XI. The lowest measured luminance value in the second measurement set could have been caused by extraneous light sources in the scene when the headlightsoff measurement was made, or by a slight misorientation of the measurement vehicle away from the signs for this particular measurement (the measured luminance of the sign adjacent to the lowest-luminance sign was also relatively low, $0.5 \mathrm{~cd} / \mathrm{m}^{2}$, which is consistent with a possible difference in vehicle orientation for this pair of measurements).

Notwithstanding this single measurement, which corresponds to less than $3 \%$ of the total number of field measurements made in the present study, the measured data and corresponding RVP analyses confirm that the measured signs meet or exceed the minimum performance requirements for both types of highly reflective sign sheeting materials used in the measurement location for the present study.

\section{Sign Luminance/Visual Performance Calculation Tool}

Using the methodology described in the previous section to estimate the minimum luminance and visual performance for signs varying in geometry, color, and sign material type, a spreadsheet tool was developed to permit users to specify sign, driver and geometric characteristics and calculate the minimum values. Using data provided by the user, the main sheet of the spreadsheet tool provides a summary graph of the sign luminance and of the RVP values associated with the minimum performance specifications for a given material for a range of distances from the sign. The user inputs the following information:

- vehicle headlamp height [ft];

- driver eye height [ft];

- sign height [ft];

- lateral offset of the sign (distance to the right or left of straight ahead - right is positive and left is negative) [ft];

- sign tilt [deg];

- background color (white, yellow, orange, red, green, blue or brown);

- sheeting type (ASTM type I, II, III, IV, V, VI, VIII, IX or XI);

- letter height [inch];

- windshield transmittance, a unitless quantity from 0 to 1 ;

- driver age [years]. 
Based on the measured data from Bullough et al. (2010) it is assumed that the luminance contrast of the letters against the background is always high (0.8) by design. Default values for common situations (vehicle types, sign locations) are provided. For $100 \mathrm{ft}(30.5 \mathrm{~m})$ intervals from the sign ranging from $100 \mathrm{ft}(30.5 \mathrm{~m})$ to $1000 \mathrm{ft}(305 \mathrm{~m})$, the spreadsheet displays the entrance and observation angles corresponding to the geometry, the luminous intensity from market-weighted median US low beam headlamps published by Schoettle et al. (2004) in the direction of the sign, the minimum coefficient of retroreflection for the geometric configuration (if applicable; some distances might result in angles outside the defined boundaries for some material specifications), and the resulting luminance and RVP curves for these distances. When data are outside the range the spreadsheet returns a blank or 'N/A' value.

Individual tabs within the spreadsheet tool contain the interim calculations for interpolating the headlamp intensity for each geometry, for identifying the retrore- flection coefficient for each material, color and entrance/ observation angles (using a lookup table), and for calculating visibility using the RVP model. Fig. 6 shows the main screen for one particular sign calculation scenario, a green overhead sign using ASTM D4956-16 Type XI material, viewed by the driver of a passenger car. The spreadsheet tool can be downloaded from NYSDOT (2016).

\section{Toward Performance Specifications}

An objective of sign material selection is to ensure high levels of visibility and legibility of the signs, without using materials that might produce luminances much higher than needed for adequate visibility. An RVP level of 0.8 is considered (Rea 1989) to be one that ensures a high level of visual performance. In multiple studies of nighttime driver visibility, this level of performance has been found to be associated with consistent detection and identification of objects and potential hazards along the roadway (Bullough, Radetsky 2014).

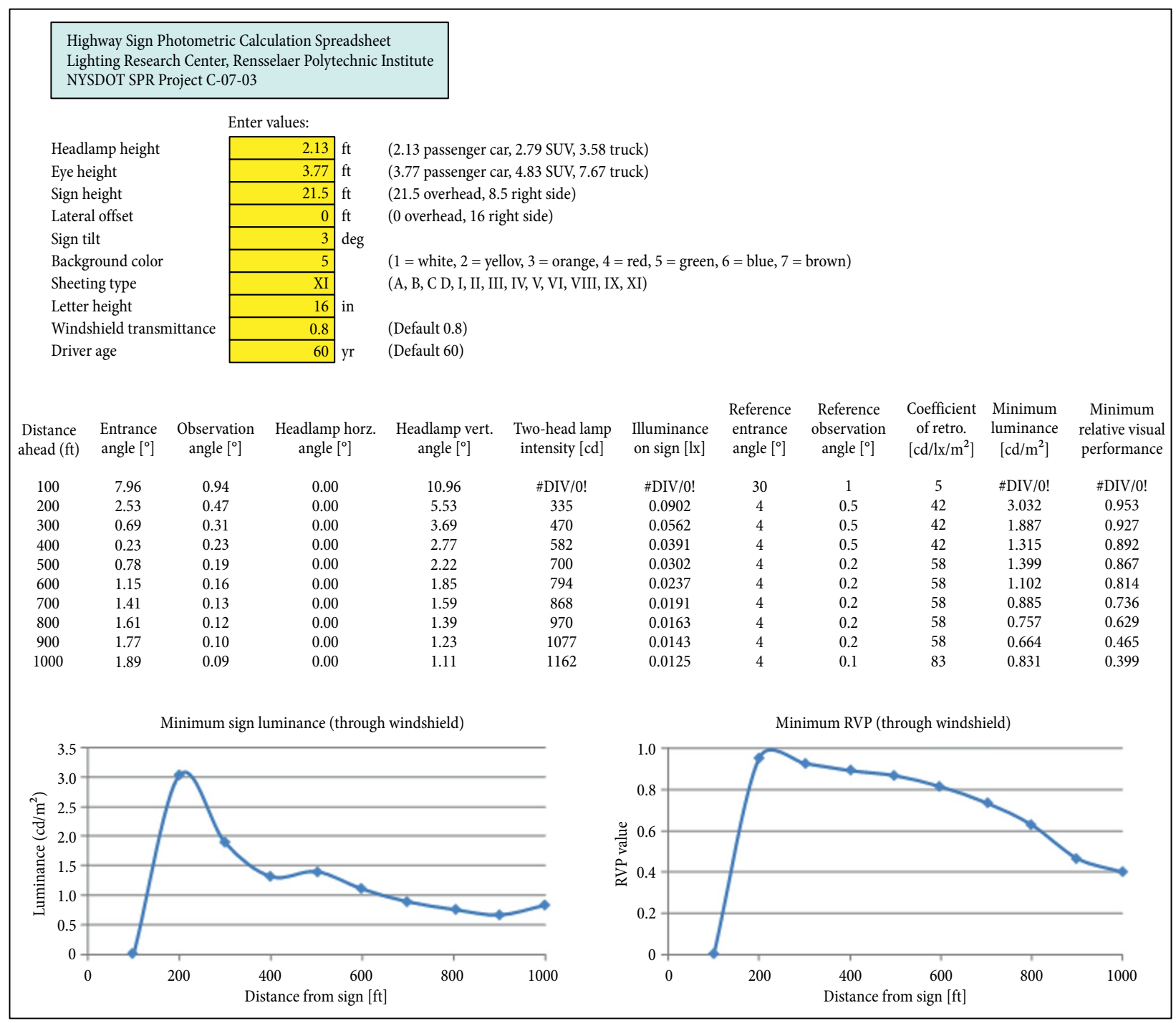

Fig. 6. Main screen of the spreadsheet tool showing calculated luminances and RVP values for a green overhead sign using ASTM D4956-16 type XI material 
Carlson et al. (2010) suggest that based on driver eye-movement data, that viewing distances between $320 \mathrm{ft}(98 \mathrm{~m})$ from the sign out to $640 \mathrm{ft}(195 \mathrm{~m})$ from the sign are those at which most sign reading is likely to occur. Given these considerations, one possible performance specification could be to achieve a minimum RVP value of 0.8 for distances from the sign between $320 \mathrm{ft}(98 \mathrm{~m})$ and $640 \mathrm{ft}(195 \mathrm{~m})$. Fig. 7 shows the minimum RVP profile for a green overhead sign (mounted $21.5 \mathrm{ft}(6.6 \mathrm{~m})$ above the ground with a $3^{\circ}$ tilt, with 16 inch $(40.5 \mathrm{~cm})$ characters, as viewed by a 60 -year-old driver of a sport utility vehicle) using ASTM D4956-16 Type III material; the minimum RVP values drop below 0.8 between these distances. If the ASTM material type is changed to Type XI, the minimum RVP values remain at or above 0.8 between these distances.

\section{Conclusions}

The present paper describes a series of investigations to identify a process for design that can help to ensure specified levels of performance in terms of a driver's ability to read and identify information on highway signage. The procedure uses published data on headlamp photometric performance in the past decade, and is based on present specifications for sign materials published by ASTM D4956-16. It also uses a visual performance model (Rea and Ouellette, 1991) that has been found to be related to visual response and identification times in simulated sign viewing conditions (Goodspeed, Rea 1999; Schnell et al. 2009) as well as in outdoor field studies of visual object detection and identification (Bullough, Radetsky 2014).

The present study also resulted in a useful procedure for conducting field measurements along busy highways at night with a minimum of disruption to traffic. Portable luminance meters like the one used in these field measurements yielded consistent and reasonable measurement values based on the results of both sets of measurements, and can distinguish among different sign sheeting types (e.g., between ASTM Type IX and Type XI). It is important to consider, however, that field or laboratory measurements of luminance will nearly always yield higher luminance values than would be predicted from the sheeting specifications themselves; this is due to the limited number of angles at which performance is defined in these specifications. Nonetheless, they are useful because the calculations based on the performance specifications provide the minimum floor of performance than can be expected.

Thus, the luminances and visual performance values predicted by the spreadsheet calculation tool described in this paper are conservative, because they allow the user to estimate, for what appears to be the first time, the minimum performance that could be expected for given geometric and lighting conditions. In comparison, the field measurements conducted in the present study nearly always show substantially higher luminances than predicted by the calculation procedure that was developed. While tools exist from some manufacturers
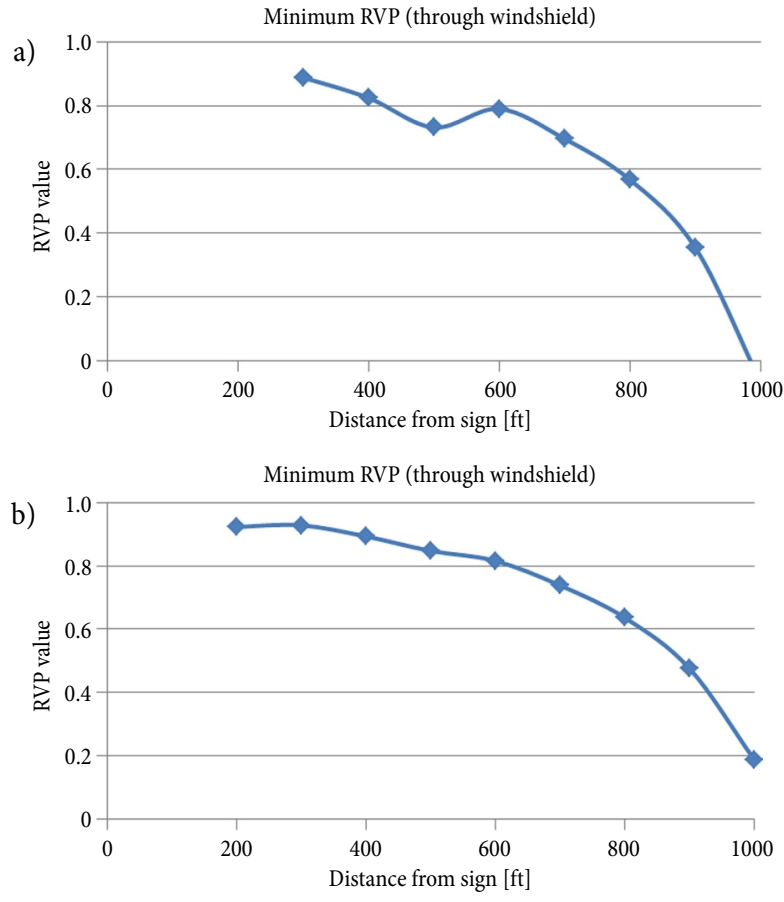

Fig. 7. Minimum RVP values for a green overhead sign at different distances: a - ASTM Type III material; b - ASTM Type XI material

that may allow the user to evaluate a specific manufacturer's sheeting materials (because the manufacturer can provide much greater detail about the performance of its sheeting than the sparse information included in generic (ASTM D4956-16) performance specifications), a tool for characterizing the minimum level of performance based on generic specifications has heretofore not been available.

\section{Acknowledgements}

This study was sponsored by the New York State Department of Transportation (NYSDOT), in part with funds from the Federal Highway Administration (FHWA). The project was administered through the Region 2 University Transportation Research Center (UTRC) at the City University of New York under the direction of Dr. Camille Kamga of UTRC. Patrick Galarza from NYSDOT served as the project manager. Helpful input to the project was provided by Barbara Abrahamer, Rajendra Amin, Moysey Eppel, Pratip Lahiri, Fred Lai, Kevin Ledlon, Carlos Quiles and Ramesh Ramanathan from NYSDOT Main Office and Region 11; and by Emmett McDevitt from FHWA. Mark Rea and Ute Besenecker from the Lighting Research Center (LRC) made important technical contributions.

\section{References}

ASTM D4956-16. Standard Specification for Retroreflective Sheeting for Traffic Control. American Society for Testing and Materials (ASTM). http://doi.org/10.1520/D4956-16B

Bullough, J. D.; Radetsky, L. C. 2014. Roadway lighting, relative visual performance and safety, in Proceedings of the Illu- 
minating Engineering Society Annual Conference 2014, 2-4 November 2014, Pittsburgh, Pennsylvania, US, 203-207.

Bullough, J. D.; Skinner, N. P.; O’Rourke, C. P. 2010. Legibility of urban highway traffic signs using new retroreflective materials, Transport 25(3): 229-236. http://doi.org/10.3846/transport.2010.28

Carlson, P.; Miles, J.; Park, E. S.; Young, S.; Chrysler, S.; Clark, J. 2010. Development of a Model Performance-Based Sign Sheeting Specification Based on the Evaluation of Nighttime Traffic Signs Using Legibility and Eye-Tracker Data. Report No FHWA/TX-10/0-5235-1-VOL1. Texas Transportation Institute, Texas A\&M University, US. 190 p. Available from Internet: http://tti.tamu.edu/documents/0-5235-1-VOL1.pdf

Goodspeed, C.; Rea, M. S. 1999. The significance of surround conditions for roadway signs, Journal of the Illuminating Engineering Society 28(1): 164-173. http://doi.org/10.1080/00994480.1999.10748263

NYSDOT. 2016. Sign Calculator. New York State Department of Transportation (NYSDOT). Available from Internet: http://www.dot.ny.gov/divisions/engineering/technicalservices/trans-r-and-d-repository/NYSDOT-C-07-03-SignCalculator.xls

Ré, J. M.; Miles, J.; Carlson, P. J. 2011. Analysis of in-service traffic sign retroreflectivity and deterioration rates in Texas, Transportation Research Record: Journal of the Transportation Research Board 2258: 88-94. http://doi.org/10.3141/2258-11

Rea, M. S. 1989. Visibility criteria and application techniques for roadway lighting, Transportation Research Record: Journal of the Transportation Research Board 1247: 12-16.

Rea, M. S.; Ouellette, M. J. 1991. Relative visual performance: a basis for application, Lighting Research and Technology 23(3): 133-144. http://doi.org/10.1177/096032719102300301

Schnell, T.; Yekhshatyan, L.; Daiker, R. 2009. Effect of luminance and text size on information acquisition time from traffic signs, Transportation Research Record: Journal of the Transportation Research Board 2122: 52-62. http://doi.org/10.3141/2122-07

Schoettle, B.; Sivak, M.; Flannagan, M. J.; Kosmatka, W. J. 2004. A Market-Weighted Description of Low-Beam Headlighting Patterns in the U.S.: 2004. Report No. UMTRI-2004-23. University of Michigan, US. 18 p. Available from Internet: https://deepblue.lib.umich.edu/bitstream/ handle/2027.42/55198/UMTRI-2004-23.pdf

Skinner, N. P.; Bullough, J. D.; Smith, A. M. 2010. Survey of the present state of headlamp aim, in TRB 89th Annual Meeting Compendium of Papers DVD, 10-14 January 2010, Washington, DC. 